\title{
Sleeping sickness in Uganda: a thin line between two fatal diseases
}

Kim Picozzi, Eric M Fèvre, Martin Odiit, Mark Carrington, Mark C Eisler, Ian Maudlin, Susan C Welburn

Centre for

Infectious Diseases,

Royal (Dick) School

of Veterinary

Studies, College of

Medicine and

Veterinary Medicine,

University of

Edinburgh,

Edinburgh

EH25 9RG

Kim Picozzi

molecular biologist

Eric M Fèvre

epidemiologist

Mark C Eisler

veterinary

epidemiologist

Ian Maudlin

epidemiologist

Susan C Welburn

molecular

epidemiologist

Ministry of Health

(Uganda),

PO Box 7272 ,

Kampala, Uganda

Martin Odiit

medical officer, tropical

diseases

Department of

Biochemistry,

University of

Cambridge,

Cambridge

CB2 1GA

Mark Carrington

molecular and

biochemical

parasitologist

Correspondence to:

S C Welburn

sue.welburn@

ed.ac.uk

BMJ 2005;331:1238-42

\begin{abstract}
Objective To determine, through the use of molecular diagnostic tools, whether the two species of parasite that cause human African trypanosomiasis have become sympatric.

Design Blood sampling of all available patients between June 2001 and June 2005 in central Uganda and between July and September 2003 in northwest Uganda and analysis of subcounty sleeping sickness records in Uganda between 1985 and 2005.

Setting Sleeping sickness treatment centres in central and northwest Uganda and in south Sudan.
\end{abstract}

Participants Patients presenting at the treatment centres and diagnosed as having sleeping sickness. Main outcome measure Classification of parasites from patients from each disease focus as either Trypanosoma brucei rhodesiense (acute form) or $T b$ gambiense (chronic form).

Results Blood from 231 patients with sleeping sickness in central Uganda and from 91 patients with sleeping sickness in northwest Uganda and south Sudan were screened for $T b$ rhodesiense (detection of SRA gene) and $T b$ gambiense (detection of TgsGP gene). All samples from central Uganda were classified as $T b$ rhodesiense, and all samples from northwest Uganda and south Sudan were identified as Tb gambiense.

Conclusions The two focuses of human African trypanosomiasis remain discrete, but the area of Uganda affected by the acute form of human sleeping sickness has increased 2.5-fold since 1985, spreading to three new districts within the past five years through movement of infected livestock. Without preventive action targeted at the livestock reservoir of this zoonotic disease, it is likely that the two disease focuses will converge. This will have a major impact on diagnosis and treatment of this neglected disease. Real time monitoring is recommended, using molecular diagnostic tools (at a regional surveillance centre, for example) targeted at both livestock and human patients.

\section{Introduction}

Human African trypanosomiasis, or sleeping sickness, is responsible for an estimated 100000 deaths every year. ${ }^{1}$ Two pathogens are involved: Trypanosoma brucei rhodesiense, which causes an acute form of disease, and $T b$ gambiense, the chronic form. $T b$ rhodesiense is found in east Africa, and $T b$ gambiense is present in central and west Africa. ${ }^{2}$ Uganda represents a region of potential overlap, with the two focuses expanding towards each other. ${ }^{3-7}$

Sleeping sickness was first recognised in southeast Uganda in 1898 and in the north west of the country in 1902. ${ }^{8}$ Refugee movements have spread $T b$ gambiense to form a contiguous focus with south Sudan, ${ }^{10-12}$ raising the possibility that refugees may carry $T b$ gambiense into areas endemic for $T b$ rhodesiense.

Animals were implicated in the transmission of $T b$ rhodesiense disease during the 1940 s epidemic in Busoga, southeast Uganda. ${ }^{13}$ The disease re-emerged in Busoga between 1976 and 1983, when 19974 patients had the disease diagnosed..$^{14}$ An outbreak of $T$ $b$ rhodesiense in Tororo district to the east of the Busoga focus in 1988 was brought under control by 1995 but not before 1180 cases had presented. Cattle restocking has been implicated in the latest outbreak of $T b$ rhodesiense disease in $2000,{ }^{15}$ in which $18 \%$ of cattle were found to be carrying the human pathogen. ${ }^{16}$ The disease has since spread to two adjacent districts ${ }^{17}$; the $T$ $b$ rhodesiense and $T b$ gambiense focuses are predicted to merge, complicating diagnosis and treatment. ${ }^{118}$

Microscopy of blood, lymph, or cerebrospinal fluid informs treatment of $T$ b rhodesiense. $T$ b gambiense may not be evident by microscopy, and diagnosis is based on the card agglutination test for trypanosomiasis, ${ }^{19}$ which is ineffective for diagnosis of $T b$ rhodesiense. Drugs for the treatment of early stage disease differ ${ }^{20}$ : pentamidine, the first line drug for $T b$ gambiense, is not effective against early stage $T b$ rhodesiense, ${ }^{21}$ which is treated with suramin. Late stage cases of both diseases are treated with melarsoprol. The number of treatment failures of late stage $T b$ gambiense is increasing; eflornithine is used in these cases but is not effective against late stage $T b$ rhodesiense. ${ }^{1}$ Overlap in the distribution of these parasites would complicate diagnosis and result in inappropriate treatment for critically ill patients.

We used molecular tools to examine the current distribution of the two parasite species in Uganda. Specifically, we observed the historical spread of disease in terms of land area affected and population at risk and identified sleeping sickness parasites from the two focuses.

\section{Methods}

Sleeping sickness and geographical area

Disease records for sleeping sickness across Uganda came from the Co-ordinating Centre for Trypanosomiasis in Uganda and from sleeping sickness treatment centres in affected regions. We obtained digital data for Uganda ${ }^{22}$ from the geographical information system, ArcView 3.2 (Redlands, CA, USA) to determine the size of geographical areas affected through time. The administrative units shown on the map (figure) are districts, the highest administrative unit in Uganda. We determined the distribution of the

An appendix is on bmj.com 
Table 1 Molecular analysis of samples isolated from patients with confirmed sleeping sickness

\begin{tabular}{lcccc}
\hline & \multicolumn{4}{c}{ Result of gene screen } \\
\hline Location & $\begin{array}{c}\text { No of samples } \\
\text { screened }\end{array}$ & $\begin{array}{c}\text { HCGA } \\
\text { positive }\end{array}$ & $\begin{array}{c}\text { TgsGP } \\
\text { positive }\end{array}$ & $\begin{array}{c}\text { SRA } \\
\text { positive }\end{array}$ \\
\hline b rhodesiense focus & & & & \\
\hline Soroti district & 210 & 210 & 0 & 210 \\
\hline Kaberamaido district & 19 & 19 & 0 & 19 \\
\hline Lira district & 2 & 2 & 0 & 2 \\
\hline Total & 231 & 231 & 0 & 231
\end{tabular}

\begin{tabular}{lllll}
\hline $\boldsymbol{T}$ b gambiense focus & & & & \\
\hline Arua district, West Nile & 27 & 27 & 27 & 0 \\
\hline Kiri, south Sudan & 21 & 21 & 21 & 0 \\
\hline Tambura, south Sudan & 31 & 31 & 31 & 0 \\
\hline lbba, south Sudan & 12 & 12 & 12 & 0 \\
\hline Total & 91 & 91 & 91 & 0 \\
\hline
\end{tabular}

Control

\begin{tabular}{lllll}
\hline Akuem Bahr el Ghazal§ & 32 & 32 & 0 & 0
\end{tabular}

*Human DNA present.

$\dagger T$ b gambiense DNA present

$\ddagger T$ b rhodesiense DNA present.

§Region in Sudan unaffected by either form of human sleeping sickness

disease at the level of the subcounty (a lower unit). We calculated the area of each region at risk from the total land area of the relevant administrative (district level) units and determined the population at risk from the 2002 national population and housing census. ${ }^{23}$

\section{Clinical samples}

In southeast Uganda we obtained blood samples from 231 self reporting patients with sleeping sickness from Soroti, Kaberamaido, and Lira districts who attended Serere Health Centre between June 2001 and June 2005 (Soroti: $2001 \mathrm{n}=10,2002 \mathrm{n}=46,2003 \mathrm{n}=69$, $2004 \mathrm{n}=30$, and $2005 \mathrm{n}=55$; Kaberamaido: 2004 $\mathrm{n}=15$, $2005 \mathrm{n}=4$; Lira $2004 \mathrm{n}=1,2005 \mathrm{n}=1$ ). We examined the samples to characterise the trypanosome parasites present (table 1).

In northwest Uganda and south Sudan we examined blood samples from 91 patients from the West Nile/south Sudan focus to characterise the parasites present in human blood. These comprised samples from 27 patients attending Omugo Health Centre, Arua District (West Nile region) and from 64 patients from three health centres in south Sudan (Kiri $\mathrm{n}=21$, Ibba $\mathrm{n}=12$, Tambura $\mathrm{n}=31$ ) between July and September 2003 (table 1). We also collected samples from 32 pyrexic patients at Akuem Bahr el Ghazal, Sudan, outside the sleeping sickness focus, for use as negative control samples for both $T b$ rhodesiense and $T$ $b$ gambiense (table 1).

We included all patients who presented for treatment during the study and were diagnosed as having sleeping sickness by clinic staff. The molecular tools used in this study were applied post hoc-the diagnosis of sleeping sickness was made in the relevant clinics according to standard protocols.

\section{Polymerase chain reaction analysis}

Patients parasitologically positive for sleeping sickness were asked to provide a finger prick sample of blood, which was applied to a DNA binding matrix (FTA card, Whatman). The local health services obtained consent from patients, and agreement or otherwise did not compromise their access to treatment. We prepared FTA cards containing blood samples from sleeping

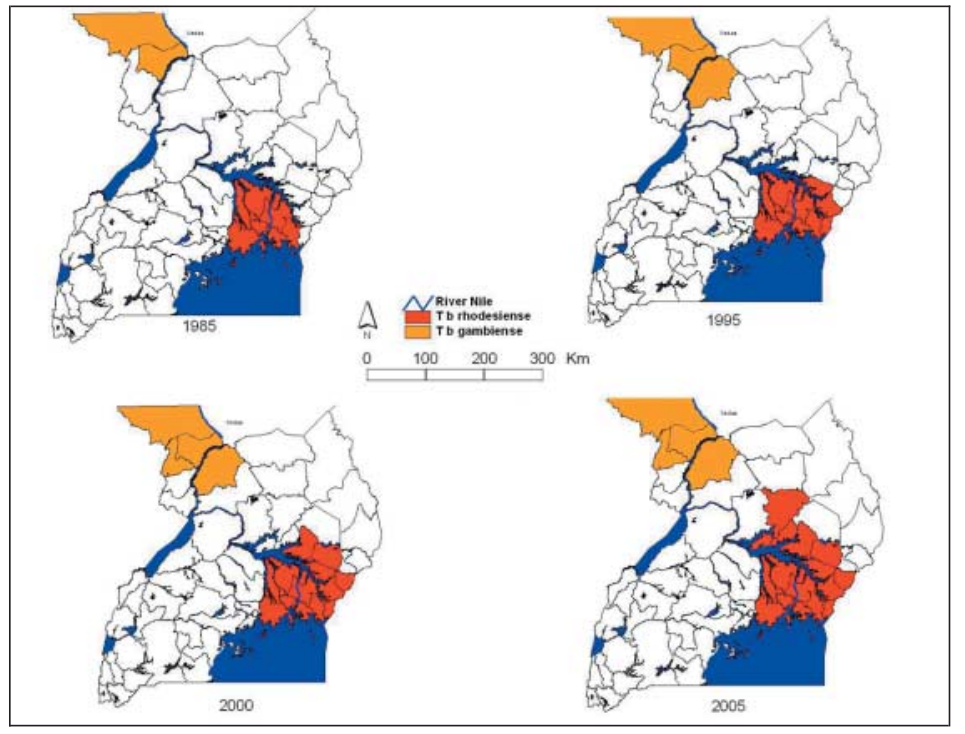

Sequential maps of areas of Uganda affected by sleeping sickness. $T$ g gambiense (in orange) occurs in south Sudan and northwest Uganda, where substantial human population movements have occurred as a result of civil instability. $T$ b rhodesiense (in red) has been spreading since the mid-1980s, and its transmission is now occurring within $150 \mathrm{~km}$ of the $T$ $b$ gambiense active focus. The tsetse belt for Glossina fuscipes fuscipes extends right across the region ${ }^{24}$

sickness patients for polymerase chain reaction (PCR) as previously described. ${ }^{25}$ Full details of the PCR methods are provided in the appendix on bmj.com. Briefly, we firstly screened samples from all areas for the presence of human DNA (using human cytoskeletal gamma actin-HCGA), to confirm that the sample contained suitable DNA for PCR amplification. We screened all samples with generic Trypanozoon primers to identify the presence of $T$ brucei sl DNA. ${ }^{26} \mathrm{We}$ screened all Trypanozoon positive samples for $T$ b gambiense (with primers for TgsGP ${ }^{27}{ }^{28}$ ) and $T b$ rhodesiense (with primers for the human serum associated gene $\mathrm{SRA}^{1629}$. We separated PCR products by agarose $(1.5 \%)$ electrophoresis containing ethidium bromide $(0.2 \mu \mathrm{g} / \mathrm{ml})$ and visualised them on an ultraviolet transilluminator.

\section{Results}

Since the mid-1980s, the area of Uganda affected by $T$ $b$ rhodesiense sleeping sickness has increased by a factor of 2.5 , from $13820 \mathrm{~km}^{2}$ to $34843 \mathrm{~km}^{2}$, and the population at risk from $\mathrm{Tb}$ rhodesiense has doubled (table 2). Before 1985, sleeping sickness in east Uganda was restricted to districts clustered around the north shore of Lake Victoria and the source of the Nile (the traditional Busoga focus). During an epidemic that started in the late 1980s the disease spread eastwards into Tororo and Busia districts, with sporadic cases in Pallisa and Mbale districts on the Uganda-Kenya border. This epidemic in Tororo district was brought under control in the mid-1990s. However, from 1998 onwards, cases of sleeping sickness were detected in Soroti district, much further to the north; the spread of this new epidemic area was attributed to the movement of the reservoir host (domestic cattle) as a result of restocking activities in the region. Control activities that sought to contain this epidemic were largely 
Table 2 Proportional increase in area affected by $T b$ rhodesiense sleeping sickness in southeast Uganda, 1985-2005

\begin{tabular}{lcc} 
Year & Area affected $\left(\mathbf{k m}^{2}\right)$ & $\begin{array}{c}\text { Proportional increase } \\
\text { since } \mathbf{1 9 8 5}\end{array}$ \\
\hline 1985 & 13820 & 1.00 \\
\hline 1995 & 18420 & 1.33 \\
\hline 2000 & 26019 & 1.88 \\
\hline 2005 & 34843 & 2.52 \\
\hline
\end{tabular}

unsuccessful, ${ }^{150}{ }^{30}$ and the disease, having become established in Soroti district, has spread further still to Kaberamaido district and more recently to the southern edge of Lira district. ${ }^{17}$ At the same time, population movements as a result of civil instability on the Sudanese border resulted in expansion of the $T b$ gambiense focus. The affected districts in the two disease focuses are now approximately $150 \mathrm{~km}$ apart (fig).

We positively identified $T$ b gambiense alone in blood from all 91 patients with sleeping sickness from the $T b$ gambiense focus, which included patients presenting in Arua district (West Nile region), north Uganda, and from health centres in south Sudan (table 1). None of these samples from this sleeping sickness focus was amplified by the gene marker SRA specific for $T b$ rhodesiense, confirming that all patients examined were infected with $T b$ gambiense parasites. Of the 231 samples obtained from the $T b$ rhodesiense sleeping sickness outbreak in east Uganda between 2001 and 2005, all amplified the SRA gene for $T b$ rhodesiense, showing that all these patients, presenting from Soroti, Kaberamaido, and Lira, were infected with $T b$ rhodesiense and confirming SRA as a diagnostic marker for $T b$ rhodesiense sleeping sickness in East Africa ${ }^{16}$ We saw no amplification in any sample from Soroti, Kaberamaido, or Lira with TgsGP, confirming that this gene specific for $T b$ gambiense is not present in people presenting with sleeping sickness in this region (table 1).

The results presented here suggest that the parasites circulating in these two disease focuses remain discrete and confirm that the disease outbreaks in Kaberamido and Lira are attributable to $T b$ rhodesiense (acute form of sleeping sickness), confirming the recent expansion of the $T b$ rhodesiense focus. None of the 32 samples from pyrexic patients from Akuem Bahr el Ghazal in Sudan, outside the sleeping sickness focuses, that were HCGA positive for human DNA were infected with $T$ brucei sl.

\section{Discussion}

\section{Risk of overlap}

Control activities aimed at containing $T b$ rhodesiense in east Uganda have been largely ineffectual. ${ }^{15}{ }^{17}{ }^{30}$ Civil instability in the region and a lack of control measures to contain the spread of disease (such as targeting the animal reservoir by restricting through cattle movements) have resulted in cases of sleeping sickness occurring further and further northwards, closer to the $T b$ gambiense endemic area.

The $T b$ gambiense sleeping sickness focus in northwest Uganda seems to be relatively stable, but the long asymptomatic stage associated with this disease means that, without active surveillance of the human reservoir population, this parasite could spread with movements of displaced peoples in the region. In south Sudan, the absence of disease control activities for eight years after civil disturbance saw the expansion of that sleeping sickness focus and some extremely high disease prevalences (for example, 29\% at Ibbe, Marindi County ${ }^{10}$ ).

We have shown, using molecular tools, that the cases of sleeping sickness in Kaberamaido and Lira districts of Uganda are indeed due to $T b$ rhodesiense. Although a real risk of overlap with the $T b$ gambiense sleeping sickness focus remains, we found no evidence to indicate that the two active disease focuses have yet converged-that is, there is no $T b$ rhodesiense within the $T b$ gambiense sleeping sickness focus or vice versa. However, the area currently at risk from $T b$ rhodesiense does now overlap with a region affected by a $T b \mathrm{gam}$ biense outbreak in $1957 .^{31}$ The active $T b$ rhodesiense disease focus is now only $150 \mathrm{~km}$ from areas currently affected by $T \quad b$ gambiense in the north west of Uganda.

The risk of sleeping sickness spreading by means of the livestock reservoir host continues to be a public health challenge. If infected cattle continue to be traded northwards in the absence of control measures then overlap of the two disease focuses will inevitably occur. If and when overlap does occur, a rapid response including revision of established diagnostic and treatment protocols will be needed to minimise its impact. Such a surveillance programme may be difficult to sustain owing to the unstable nature of the civil situation in this part of the country. ${ }^{28}$ Currently, livestock for sale in Uganda are required to be treated at their point of origin or before sale; this forms part of the national policy for trypanosomiasis control, although it has been difficult to implement at local level..$^{30}$ Given the high cost of treating patients and implementing active screening programmes in new regions with limited human health resources, strengthening this policy and encouraging its enforcement by district authorities would seem appropriate.

Economic analysis suggests that the financial benefits of treating the animal reservoir for $T b$ rhodesiense sleeping sickness would more than cover the costs of treatment and may even result in a negative cost per disability adjusted life year averted. Treating cattle increases income from livestock, as the trypanocidal drugs used to clear infection are effective against the trypanosomes that are pathogenic to cattle as well as zoonotic $T b$ rhodesiense. Lowering the incidence of sleeping sickness by treating the animal reservoir will reduce future costs of treating human patients. ${ }^{32} \mathrm{~A}$ transsectoral assessment of costs and benefits for control of zoonotic $T b$ rhodesiense, as has been done for control of brucellosis, would seem appropriate. ${ }^{33}$ Sleeping sickness tends to affect the poorest and most disenfranchised rural communities with the least access to health care. Public health messaging and extension services are urgently needed to improve knowledge and reporting of these diseases. 


\section{What is already known on this topic}

Two pathogens can cause sleeping sickness: Trypanosoma brucei rhodesiense, found in east Africa, and $T b$ gambiense, found in central and west Africa

Uganda represents a region of potential overlap between the two focuses

\section{What this study adds}

The two sleeping sickness focuses in Uganda are discrete and have not yet overlapped

They are, however, steadily converging and are now only $150 \mathrm{~km}$ apart

\section{Recommendations}

Surveillance activities should be put in to place to monitor the situation, so that any overlap in disease distribution can be detected at the earliest opportunity. As the parasites involved in $T b$ gambiense and $T b$ rhodesiense sleeping sickness are morphologically identical, such monitoring will inevitably require screening of blood samples and differentiation of the parasites with the molecular methods described here. Although these tools are not yet available at the bedside or penside, the technologies described here are applicable to a suitably equipped in-country regional laboratory targeted at both livestock and human patients at the leading edge of the sleeping sickness focuses. ${ }^{172} 29$ The continent-wide importance of these two parasite species overlapping is such that a properly equipped screening laboratory and staff training should be set up as a matter of urgency. This might take the form of an internationally funded and locally managed facility under the supervision of the relevant authorities in Uganda. Given the economic impact of trypanosomiasis on both the livestock and human health sectors, ${ }^{34}$ this would be a cost effective proposal for management of this neglected zoonotic disease.

We are grateful to the staff of Serere Hospital, Soroti district, for their assistance with the hospital records, in particular Florence Achom. We also thank the district veterinary officer, Soroti, for assistance with livestock sampling. We thank John Enyaru and Ian Anderson, Livestock Health Research Institute, Uganda, and Charles Waiswa, Makerere University (Uganda), for technical support. We thank Tim Fison and staff from Medecins Sans Frontieres (France) and Medecins Sans Frontieres (Suisse) for assistance in collecting human samples in southern Sudan.

Contributors: All authors contributed to the literature search, study design, interpretation of results, and writing the paper. SCW is the guarantor.

Funding: This study was funded by the Animal Health Programme of the UK Department for International Development, the World Health Organization (EMF/SCW), and the Cunningham Trust (KP/SCW). The views expressed are those of the authors. The funding body had no inputs to the study design; the collection, analysis, and interpretation of data; the writing of the report; or the decision to submit the paper for publication.

Competing interests: None declared.

Ethical approval: Not needed.

1 Welburn SC, Odiit M. Recent developments in human African trypanosomiasis. Curr Opin Infect Dis 2002;15:477-84.
2 Welburn SC, Fèvre EM, Coleman PG, Odiit M, Maudlin I. Sleeping sickness: a tale of two diseases. Trends Parasitol 2001;17:19-24.

3 Hutchinson OC, Fèvre EM, Carrington M, Welburn SC. Lessons learned from the emergence of a new Trypanosoma brucei rhodesiense sleeping sickness focus in Uganda. Lancet Infect Dis 2003;3:42-5.

4 Paquet C, Castilla J, Mbulamberi D, Beaulieu MF, Etchegorry MG, Moren A. [Trypanosomiasis from Trypanosoma brucei gambiense in the center of north-west Uganda: evaluation of 5 years of control (1987-1991).] Bull of north-west Uganda: evaluation

5 Okiria R. The prevalence of human trypanosomiasis in Uganda, 1970 to 1983. East Afr Med J 1985;62:813-6.

6 Cattand PP. [Human African trypanosomiasis: the current epidemiologic situation, an alarming recrudescence of the disease.] Bull Soc Pathol Exot 1994:87:307-10.

7 Hutin YJ, Legros D, Owini V, Brown V, Lee E, Mbulamberi D, et al. Trypanosoma brucei gambiense trypanosomiasis in Terego county, northern Uganda, 1996: a lot quality assurance sampling survey. Am J Trop Med Hyg 2004;70:390-4.

8 Cook JH. Notes on cases of "sleeping sickness" occurring in the Uganda Protectorate. J Trop Med 1901;4:236-9.

9 Langlands BW. The sleeping sickness epidemic of Uganda, 1900-1920: a study in historical geography. Kampala: Makerere University College, 1967. (Occasional paper No 1.)

10 Moore A, Richer M. Re-emergence of epidemic sleeping sickness in southern Sudan. Trop Med Int Health 2001;6:342-7.

11 Moore A, Richer M, Enrile M, Losio E, Roberts J, Levy D. Resurgence of sleeping sickness in Tambura County, Sudan. Am J Trop Med Hyg 1999:61:315-8.

12 Solano P, Kone A, Garcia A, Sane B, Michel V, Michel J-F, et al. Representation spatiale des deplacements des malades dans un foyer de trypanosomose humaine africaine de Cote d'Ivoire. Med Trop (Mars) 2003;63:577-82.

13 Heisch RB, McMahon JP, Manson-Bahr PEC. The isolation of Trypanosoma rhodesiense from a bushbuck. BMJ 1958;ii:1203-4.

14 Abaru DE. Sleeping sickness in Busoga, Uganda, 1976-1983. Trop Med Parasitol 1985;36:72-6.

15 Fèvre EM, Coleman PG, Odiit M, Magona JW, Welburn SC, Woolhouse MEJ. The origins of a new Trypanosoma brucei rhodesiense sleeping sickness outbreak in eastern Uganda. Lancet 2001;358:625-8.

16 Welburn SC, Picozzi K, Fèvre EM, Coleman PG, Odiit M, Carrington M, et al. Identification of human-infective trypanosomes in animal reservoir of sleeping sickness in Uganda by means of serum-resistance-associated (SRA) gene. Lancet 2001;358:2017-9.

17 Fèvre EM, Picozzi K, Fyfe J, Waiswa C, Odiit M, Coleman PG, et al. A burgeoning epidemic of sleeping sickness in Uganda. Lancet 2005;366:745-7. 18 Ochan B. Sleeping sickness re-emerges in Uganda. BMJ 2004;328:70.

19 Magnus E, Vervoort T, Van Meirvenne N. A card agglutination test with stained trypanosomes (CATT) for the serological diagnosis of $\mathrm{T} b$ gambiense trypanosomiasis. Ann Soc Belg Med Trop 1978;58:169-76.

20 Stich A, Abel PM, Krishna S. Human African trypanosomiasis. BMJ 2002;325:202-6.

21 Apted FI. Present status of chemotherapy and chemoprophylaxis of human trypanosomiasis in the Eastern hemisphere. Pharmacol Ther 1980;11:391-413.

22 Uganda Forest Department. The national biomass study phase III project document. Kampala: Forest Department, Uganda, 1996.

23 Government of Uganda. 2002 Uganda population and housing census: main report. Entebbe: Uganda Bureau of Statistics, 2005:120.

24 Rogers DJ, Robinson TP. Tsetse distribution. In: Maudlin I, Holmes PH, Miles MA, eds. The trypanosomiases. Oxford: CABI, 2004:139-79.

25 Picozzi K, Tilley A, Fèvre EM, Coleman PG, Magona JW, Odiit M, et al. The diagnosis of trypanosome infections: applications of novel technology for reducing disease risk. Afr J Biotechnol 2002;1:39-45.

26 Moser DR, Cook GA, Ochs DE, Bailey CP, McKane MR, Donelson JE. Detection of Trypanosoma congolense and Trypanosoma brucei subspecies by DNA amplification using the polymerase chain reaction. Parasitology 1989;99:57-66.

27 Berberof M, Perez-Morga D, Pays E. A receptor-like flagellar pocket glycoprotein specific to Trypanosoma brucei gambiense. Mol Biochem Parasitol 2001;113:127-38

28 Radwanska M, Claes F, Magez S, Magnus E, Perez-Morga D, Pays E, et al. Novel primer sequences for polymerase chain reaction-based detection of Trypanosoma brucei gambiense. Am J Trop Med Hyg 2002;67:289-95.

29 De Greef C, Hamers R. The serum resistance-associated (SRA) gene of Trypanosoma brucei rhodesiense encodes a variant surface glycoprotein-like protein. Mol Biochem Parasitol 1994;68:277-84.

30 Wendo C. Uganda revises cattle treatment to protect humans from sleeping sickness. Lancet 2002;359:239.

31 Morris KRS. The epidemiology of sleeping sickness in East Africa. I. A sleeping sickness outbreak in Uganda in 1957. Trans R Soc Trop Med Hyg 1959;53:384-93.

32 Shaw APM. Economics of African trypanosomiasis. In: Maudlin I, Holmes PH, Miles MA, eds. The trypanosomiases. Oxford: CABI, 2004:369402.

33 Roth F, Zinsstag J, Orkhorn D, Chimed-Ochir C, Hutton GCO, Carrin G, et al. Human health benefits from livestock vaccination for brucellosis: case study. Bull World Health Organ 2003;81:867-76.

34 Kioy D, Mattock N. Control of sleeping sickness-time to integrate approaches. Lancet 2005;366:695-6.

(Accepted 24 October 2005) 